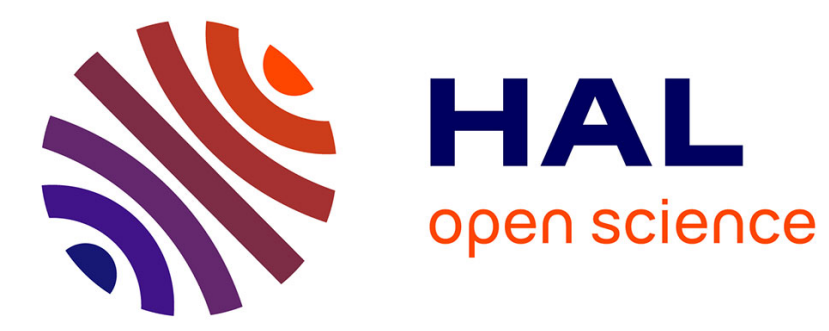

\title{
Preferences for urban green spaces and peri-urban forests: An analysis of stated residential choices
}

\author{
Gengyang Tu, Jens Abildtrup, Serge S. Garcia
}

\section{To cite this version:}

Gengyang Tu, Jens Abildtrup, Serge S. Garcia. Preferences for urban green spaces and peri-urban forests: An analysis of stated residential choices. Landscape and Urban Planning, 2016, 148 (April 2016), pp.120-131. 10.1016/j.landurbplan.2015.12.013 . hal-01292350

\section{HAL Id: hal-01292350 \\ https://hal.science/hal-01292350}

Submitted on 22 Mar 2016

HAL is a multi-disciplinary open access archive for the deposit and dissemination of scientific research documents, whether they are published or not. The documents may come from teaching and research institutions in France or abroad, or from public or private research centers.
L'archive ouverte pluridisciplinaire HAL, est destinée au dépôt et à la diffusion de documents scientifiques de niveau recherche, publiés ou non, émanant des établissements d'enseignement et de recherche français ou étrangers, des laboratoires publics ou privés. 
Research Paper

\title{
Preferences for urban green spaces and peri-urban forests: An analysis of stated residential choices
}

\author{
Gengyang $\mathrm{Tu}^{\mathrm{a}, \mathrm{b}, *}$, Jens Abildtrup ${ }^{\mathrm{a}}$, Serge Garcia ${ }^{\mathrm{a}}$ \\ a Laboratoire d'Economie Forestière, AgroParisTech, INRA, 54000, Nancy, France \\ b Université de Lorraine, 34 cours Léopold CS 25233, 54052 Nancy Cedex, France
}

\section{H I G H L I G H T S}

- Applying a choice experiment, we assess the preferences for living close to urban parks and forests.

- This study applies a pivot-based experimental design that frames respondents' choices in terms of their current residence.

- The preference heterogeneity in the population can be partially explained by differences in household characteristics.

- The results indicate substitution between having access to a private garden and to urban green spaces.

\section{A R T I C L E I N F O}

\section{Article history:}

Received 1 May 2015

Received in revised form

17 December 2015

Accepted 19 December 2015

\section{Keywords:}

Choice experiment

Residential location

Urban green spaces

Recreation

Mixed logit

Willingness to pay space

\begin{abstract}
A B S T R A C T
This paper assesses the value of urban green spaces, specifically peri-urban forests and their potential substitutes, for the local population on the basis of their residential choice. We applied a choice experiment that focuses on the trade-offs between private housing characteristics and the environmental aspects of neighborhoods. Individual willingness-to-pay is estimated from a latent class model and a mixed logit model along with a Willingness-To-Pay (WTP) space approach. Our results show that green spaces provide both direct use value (recreation) and indirect use value (scenic view). The respondent's value of distance to peri-urban forests depends on recreational use. The ownership of a private garden reduces the WTP for living closer to an urban park.
\end{abstract}

(C) 2015 Elsevier B.V. All rights reserved.

\section{Introduction}

Peri-urban forests located in between an urban core and a rural landscape generate both recreational and amenity benefits. On the one hand, the proximity of forests provides esthetic benefits such as scenic amenities (Cavailhès et al., 2010; Sander \& Polasky, 2009). On the other hand, having forests in the vicinity of the residence also provides recreational value (Ezebilo, Boman, Mattsson, Lindhagen, and Mbongo, 2015). We know from studies that evaluate outdoor recreation that the WTP for access to a given recreational site decreases with increasing transportation costs (Phaneuf \& Smith, 2005). In the meantime, an important determinant of the value of peri-urban forests is the presence of alternative urban green spaces

* Corresponding author at: Laboratoire d'Economie Forestière, AgroParisTech, INRA, 14 rue Girardet, 54000 Nancy, France.

E-mail address: gengyang.tu@nancy.inra.fr (G. Tu). in the vicinity. In particular, urban parks can also provide esthetic benefits and serve as recreational sites, making them the most likely substitute sites for peri-urban forests (Chiesura, 2004). The degree to which urban parks may be substituted by forests in the proximity of the residence has only received minor attention in the literature (Mansfield, Pattanayak, Mcdow, Mcdonald, and Halpin, 2005). Nevertheless, the assessment of the preferences for these two types of green spaces and the understanding of the potential substitution effects are important information for public urban planners. Furthermore, private gardens and public green spaces may also, to some degree, be substitutes in terms of the demand for recreation sites (Barbosa et al., 2007). For example, if one decides to sunbathe and has a garden, she can choose between going to a park or to her own private garden. However, in other aspects, these two types of sites play different roles (Kellett, 1982). So far, few studies have dealt with the role of owning a private garden in a person's WTP for having access to public parks (Panduro \& Veie, 2013). 
A large body of research documents the positive impact of urban green spaces on local residents' welfare. This includes hedonic studies showing that house and land prices rise with proximity to forests (e.g., Mansfield et al., 2005; Thorsnes, 2002; Tyrvainen \& Miettinen, 2000), or increase with the proportion of forest land in the region (Hand, Thacher, McCollum, and Berrens, 2008), and that access to urban parks has a significant value for the local population as well (Hoshino \& Kuriyama, 2010; Poudyal, Hodges, \& Merrett, 2009; Sander \& Polasky, 2009). Significant values of access to parks have also been estimated using stated preference (SP) methods (Brander \& Koetse, 2011; Del Saz Salazar \& García Menéndez, 2007). The provision of urban green spaces may also contribute to the building of an attractive image of a city or a neighborhood, thus influencing the residential choice of newcomers. For example, in Nancy (France), where the empirical part of this study was carried out, the local government has attempted to build an attractive image by making the city "green and pleasant" (report from Nancy's Urban Development Committee, 2011). Therefore, knowledge about the role of urban green spaces in the choice of residence location constitutes important information for urban planners. While the value of urban green spaces for inhabitants has been estimated in numerous studies that apply the hedonic pricing method and the contingent evaluation method, information on how different types of green spaces, i.e., urban parks and peri-urban forests, interact is lacking, as are appropriate empirical methods for analyzing this issue. We propose choice experiments (CE) as a suitable empirical method in spite of their hitherto limited number of applications in the valuation of urban green spaces (Bullock, 2008; Giergiczny \& Kronenberg, 2014).

In this context, our study aims to estimate the non-market value of peri-urban forests for the local population through homeowners' residential location choices. Our SP data is obtained from a face-to-face survey carried out in the urban agglomeration of the city of Nancy, France, in the summer of 2013. The preferences of respondents are revealed through a $\mathrm{CE}$ where we propose alternative residences to them. We model residential choice by applying a random utility model (RUM). Specifically, we chose to use mixed logit (ML) and latent class (LC) models to account for preference heterogeneity. A main advantage of using a CE method is that by applying an experimental design, we avoid issues of correlated omitted variables, endogeneity of explanatory variables and multicollinearity, which is often a problem with revealed preference data used in applications of the hedonic pricing model (e.g., Earnhart, 2002; Freeman, 1993). Moreover, compared to contingent valuation, a multi-attribute discrete choice model makes it possible to estimate the trade-offs between private housing and green space attributes.

This paper is organized as follows. In the following section, we present our empirical strategy by describing the theoretical background, the CE design, and the survey carried out in the city of Nancy, France. In Section 3, we present the econometric specification we used and the way we estimate individual WTPs. In Section 4 , we present the estimation results, Section 5 is devoted to a discussion and Section 6 concludes the paper.

\section{Empirical strategy}

\subsection{Residential choice and $C E$}

The CE method is based on the Lancasterian consumer theory (Lancaster, 1966), combined with the random utility theory (RUM, McFadden, 1974). The central assumption of the CE method is that the utility derived from any option depends on the attributes/characteristics of the goods. It involves the generation and analysis of choice data through the construction of a hypothetical market using a survey. This method is therefore generally considered as an appropriate method for the valuation of multi-attribute non-market goods or to analyze preferences for new product attributes of market goods (Henley, Wright, and Adamowicz, 1998; Louviere, 1992).

In the present study, we construct a hypothetical market for residential choice. According to Prashker, Shiftan, and Hershkovitch-Sarusi (2008), the attributes that influence the residential choice decisions can be broken down into four categories: dwelling unit characteristics (size, type of house, parking, etc.); neighborhood characteristics (safety, traffic, noise and air pollution); accessibility characteristics (working places, schools, shopping and leisure opportunities); and individual characteristics (education, age, income, etc.). Attributes considered in previous studies that apply the CE method to residential choice found that characteristics such as accessibility (Kim, Pagliara, and Preston, 2005; Liao, Farber, and Ewing, 2015) and the environmental quality of the neighborhood (Phaneuf, Taylor, and Braden, 2013) have an impact on the residential location choice. Walker and Li (2007) show that the importance of these attributes depends on the household's life style. So far, there is not any application of CE to the housing choice in the literature on the valuation of urban greenery. Nevertheless, pioneered by Adamowicz, Louviere, and Williams (1994), the CE method is an appropriate and widelyused approach in the valuation of the environment and amenities (e.g., Hanley, Wright, and Koop, 2002). Applying the CE method, the purpose of this study is to estimate the benefits that people gain from living close to peri-urban forests and urban parks by studying their residential location choice. While peri-urban forests and urban parks are normally considered as exploitable non-market goods, e.g., in the hedonic pricing model, they are attributes of housing, which is a market good. The idea behind our CE is to make the respondents state their preferences for different housing, which varies with respect to access to green spaces.

One advantage of using a CE is to be able to avoid multicollinearity among attributes since attribute levels are considered to be orthogonal in experimental designs (Earnhart, 2002). The large number of potential attributes that have an impact on housing prices and multicollinearity among these attributes may complicate the econometric analysis, i.e., low significance levels due to high standard errors and large changes in parameter estimates given a small change in the data or model specification (Irwin, 2002). Multicollinearity may be caused by the fact that households with the same preferences (and same socio-demographic characteristics) would choose the same location. For example, higher income households will, on average, reside in neighborhoods with larger houses with more bathrooms, larger gardens located within a certain distance from the city center, and with access to better schools. Another advantage of the CE method is the possibility of ex ante modeling of new green spaces. The last problem that we could solve with $\mathrm{CE}$, and that may be the most important, is the problem of omitted variable bias (Bockstael \& McConnell, 2007). Unobservable neighborhood characteristics that matter to households are often expected to be correlated with the amenity of interest (Kuminoff, Parmeter, and Pope, 2010). Crime rates are often lower in neighborhoods with high-income households, and high-income households will, in general, be found in locations with easy access to green spaces. If crime rates are not included in the hedonic model due to missing data, the estimated values of being close to green spaces will be upward-biased. In CE studies, the attributes of interest, in our case, access to green spaces, are specified in an experimental design. Therefore, before the respondents make their choices between different housing alternatives, we ask them to only consider the attributes specified in the experiment while considering that all other attributes 
(e.g., crime rates) are the same as in their current housing situation.

\subsection{Experimental design}

Studies using CE to elicit individuals' preferences rely on an experimental design. A number of important decisions should be made at the design stage, which includes identifying relevant residential attributes and their levels. In order to focus on the trade-offs between private housing characteristics and the environmental attributes of a neighborhood, five attributes affecting residential choice and their levels were identified. This choice is based on meetings with experts from the Urban Development Committee of Nancy, previous surveys on forest recreation in the Lorraine region where Nancy is the largest urban agglomeration (Abildtrup, Garcia, Olsen, and Stenger, 2013), and interviews with residents in Nancy.

We applied a pivot-style experimental design. In a standard CE design, the levels of each attribute of the hypothetical alternatives are specified independently of the respondents' current situation, which leads to unrealistic design. Researchers have recently applied pivot designs where the hypothetical alternatives are pivoted around the reference alternative (Hensher, 2004; Hensher \& Green, 2003; Hensher, Greene, \& Rose, 2006; Hensher \& Rose, 2007; Train \& Wilson, 2008). The reference alternative in our CE is the respondent's actual residence. This induces more realism and can provide greater specificity than the standard approach where the hypothetical alternatives are defined independently of the respondents' current situations. The pivot design technique is based on a number of theories derived from behavioral and cognitive psychology, economics, case-based decision theory and minimum-regret theory (Gilboa, Schmeidler, \& Wakker, 2002; Kahnemann \& Tversky, 1979; Starmer, 2000). During the interview, respondents are first asked to describe their current residence with respect to the selected attributes. They are then requested to choose between three residential options. Among the options, one is their actual house. The other two hypothetical alternatives are generalized by changing the values of chosen attributes of their current house within a certain range. Other attributes of residences that are not explicitly included in the CE are assumed to be the same for all alternatives.

Table 1 presents the five attributes selected in our CE and the attribute levels. The first attribute is the "distance to peri-urban forest". Based on the spatial distribution of all peri-urban forests, interviews and experts' suggestions, we set three levels of distance to the forest. The second attribute is the "distance to parks". Urban parks are considered in our CE because they may serve as a substitute or a complementary site (Termansen, Zandersen, \& Mcclean, 2008), influencing the recreation demand of peri-urban forests. We also set three levels of distance to parks with the same method used to establish the distance to peri-urban forests. Nancy has a relatively high density of parks and forests. For those already living close to a park and/or a forest, it is difficult to do a CE with reduction of distance to a park/or a forest. If the survey has to be fully general (applicable to all residents in the selected population), then being closer for those already bordering parks and forests would be meaningless. Therefore, the levels of the "distance to forests" and
Table 1

House attributes and their levels in the CE.

\begin{tabular}{ll}
\hline Attribute & Level \\
\hline & Current \\
Distance to peri-urban forest & $2 \mathrm{~km}$ farther \\
& $4 \mathrm{~km}$ farther \\
Distance to park & Current \\
& $500 \mathrm{~m}$ farther \\
Scenic view of green spaces & $1000 \mathrm{~m}$ farther \\
& With view \\
Size of living space $\left(\mathrm{m}^{2}\right)$ & No view \\
& $-10 \%$ \\
& Current \\
& $+10 \%$ \\
Price/rent of house & $-15 \%$ \\
& $-10 \%$ \\
& $-5 \%$ \\
& Current \\
& $+5 \%$ \\
& $+10 \%$ \\
\hline
\end{tabular}

"distance to parks" attributes are only increased relatively to the levels of the reference alternative. If we assume a linear relationship between distance from home and utility, reasonable with the relative small distances applied, the WTP to avoid an increase in distance is equal to the WTP for a decrease in distance.

The attribute "scenic view of green spaces" is used to estimate the value generated by esthetic amenity. Finally, we add the size of living space and price as housing characteristic attributes. Using these important housing attributes, we are able to observe people's trade-offs between private housing amenities and environmental amenities with a limited budget. Note that we do not include all the other attributes, e.g., public infrastructure, which may influence the choice of residence. It is possible to do this since we carry out an experiment where we tell the respondents that the hypothetical alternatives are exactly the same as the current alternatives, except with respect to the five attributes in our CE.

One example of our choice scenarios is presented in Table 2. Each choice of the CE set presents three alternatives with the same five attributes. One of the three alternatives is the status quo option (current housing). The five attributes, with their different levels, have 324 combinations using a full factorial design. It is not realistic to include all alternatives in a CE. We therefore used a D-efficient design (Louviere, Hensher, \& Swait, 2000) that only made it possible to estimate the main effects and the interaction between the two attributes of distance. This interaction term was included to investigate the substitution between parks and forests. Applying Kuhfeld's method (2010) using SAS, we constructed a D-efficient design with 12 different choice sets, which are divided into four groups. Four versions of the questionnaire, one for each group of choice sets, were printed and each respondent was randomly distributed one of the four versions of the questionnaire. The question asked is: "Imagine that, at the time you chose your current residence, the following two other alternatives existed. Assuming that all other characteristics stay the same, only these five attributes vary. Which residence would you have chosen among the three options?"

Table 2

Example of a choice situation.

\begin{tabular}{|c|c|c|c|}
\hline Attributes & Current house & Alternative 1 & Alternative 2 \\
\hline Distance to forest & Current distance & $2 \mathrm{~km}$ farther & Current distance \\
\hline Distance to park & Current distance & $500 \mathrm{~m}$ farther & $1000 \mathrm{~m}$ farther \\
\hline Scenic view of green spaces & Current view & No view & With view \\
\hline Size of the house & Current size & $10 \%$ more & $10 \%$ more \\
\hline Price/rent of the house & Current price/rent & $15 \%$ less & $5 \%$ less \\
\hline I prefer (choose only one please!) $\rightarrow$ & $\square$ & $\square$ & $\square$ \\
\hline
\end{tabular}




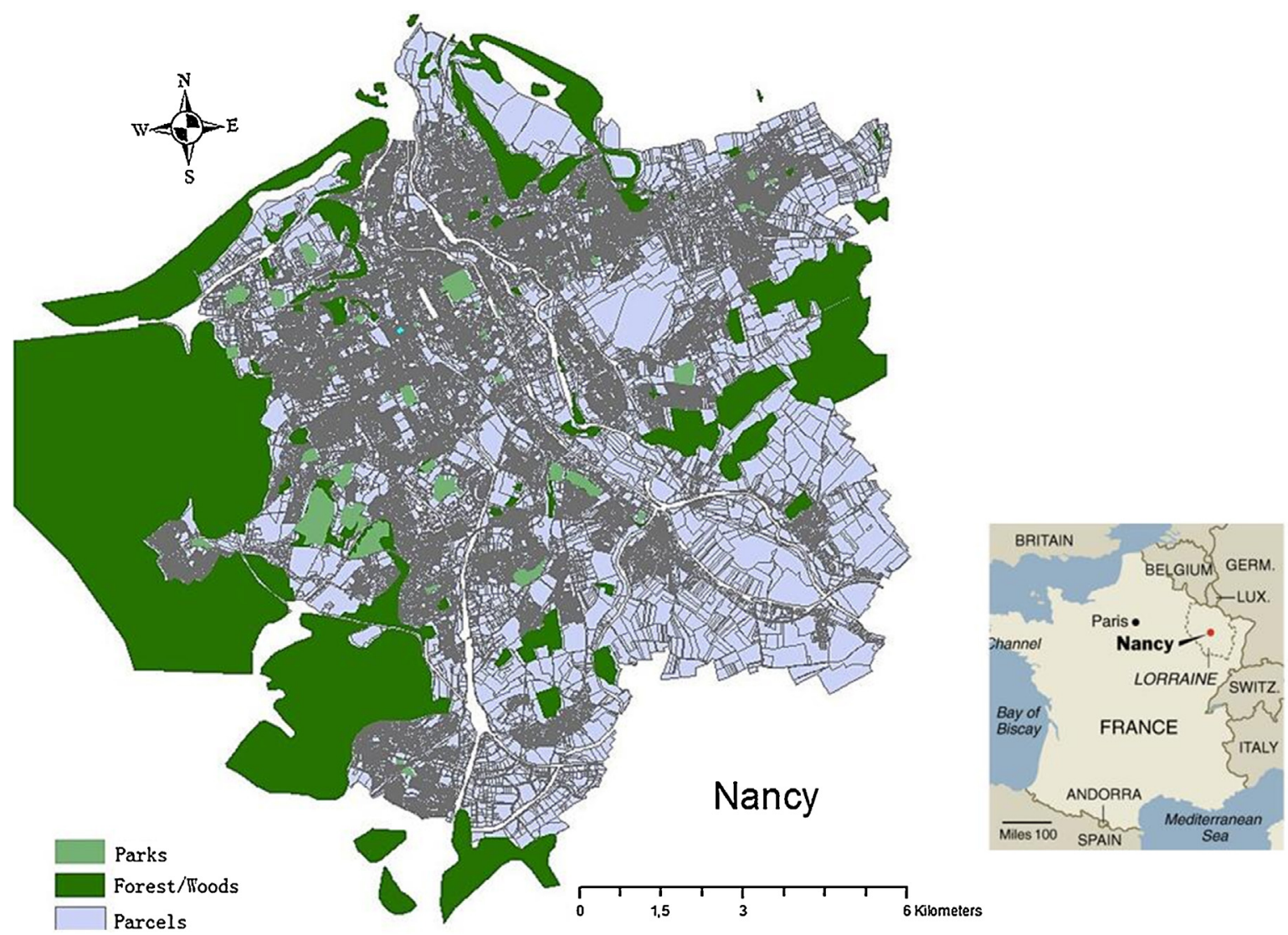

Fig. 1. The location of Nancy in France and Nancy's parks and peri-urban forests.

\subsection{Survey}

Our study area is the city of Nancy (Fig. 1), which had 124,217 households in 2006, according to the statistics of the French National Institute of Statistics and Economic Studies (INSEE). It is the biggest urban agglomeration in the Lorraine region (France). In 2013, forest covered nearly 5117.8 ha, representing $36.96 \%$ of its agglomeration, according to the French National Institute of Geographic and Forest Information. Compared to the forestry rate in France, which was 30\% in 2013, Nancy and its surrounding area is a region rich in forest resources. The public urban green space data we considered in this study includes urban parks, and private gardens. Nancy currently has 23 urban parks open to the public. These parks include spaces with individual trees but not forest cover and are very different from peri-urban forests.

Our face-to-face survey was carried out in July 2013 by a Ph.D. student and a Master's student over a period of 14 days. A number of different public places were selected where we assumed that respondents would have some time to spare, which would increase the participation rate. The survey lasted one or two days in each survey site. The main places were a municipality canteen for public servants (66 questionnaires), Parc Perpinière, the biggest park in Nancy, (35 questionnaires) and in the inner-city train (34 questionnaires). The remaining 45 questionnaires were completed at ten different locations, e.g., at the railway station, peri-urban forests, and other smaller parks. It appeared that not all of the selected places were suitable for the survey and only a few questionnaires were completed at these places (e.g., the library and the social security office, bus stops). Therefore, the final sample is not balanced with respect to survey location. However, we believe that we have obtained a convenience sample which based on comparison of key demographic characteristics seems similar to the population (Section 2.4). Furthermore, as explained in Section 4, we did not find that our results are sensitive to survey location, i.e., in parks or forests vs. other locations. The questionnaire consisted of an introduction, four main sections and a map of Nancy. The introduction briefly presented the survey and the institutions conducting it. The first section aimed to obtain information about the respondents' recreational activities, such as the number of visits to forests around Nancy. The purpose of the second section was to collect information about the respondents' actual residences, such as the size of living spaces, housing prices and scenic views of green spaces. The third section was designed to obtain respondents' personal information. Finally, a CE, like the one described above, was implemented. In each questionnaire, a map of Nancy was included to help the respondents to find the forest they lived close to and visited the most often. The respondents were all adults ( +18 years old) who live in Nancy and its surrounding area, which is our study area. All respondents were asked to provide information about their primary residence. On average, the interviews lasted $25 \mathrm{~min}$ and respondents were not remunerated. The number of people approached but who did not accept to be introduced to the questionnaire was not registered. A total of 226 people accepted to be introduced to the questionnaire and of these 180 (80\%) completed the questionnaire sufficiently to be used for our analysis.

\subsection{Data description}

In Table 3, the main demographic and socioeconomic characteristics of the effective sample (180 respondents) used to estimate the choice model are presented and compared with the total population of Nancy and its surrounding area. It shows similarities between the demographic characteristics of the sample interviewed and of the population. The percentage of women is higher. 
Table 3

Sample and population comparison.

\begin{tabular}{lll}
\hline & Sample & $\begin{array}{l}\text { Nancy and its surrounding } \\
\text { area (Source: INSEE) }\end{array}$ \\
\hline Gender distribution (\% women) & 53.5 & 47 \\
Homeowners (in \%) & 48.3 & 41.3 \\
Age distribution (in \%) & & \\
$\quad$ Under 25 years & 16.5 & 16 \\
Between 25 and 34 years & 27.6 & 18 \\
Between 35 and 64 years & 52.5 & 46 \\
Over 65 years & 3.4 & 20 \\
\hline
\end{tabular}

Considering that the respondents did not answer the questionnaire according to their own situation but based on the behavior of their family, this difference of gender distribution is expected to be relatively small. The proportion of homeowners (48.3\%) in the sample is slightly higher than the real population (41.3\%). However, in Nancy and its surrounding area, 9.1\% of the homes are either secondary residences or vacation homes. If the secondary residences are excluded, the real proportion of homeowners in Nancy will be close to the proportion of homeowners in our sample. The rate of elderly people (more than 65 years old) is lower since it is difficult to encounter them in public places. As a result, the distribution rates of all other age classes are higher. Although the difference of age distribution between the sample and the studied population may raise some concerns regarding the representativeness of the sample, we do not believe that this will change the main conclusions of this paper. This is also indicated by an insignificant effect of respondent's age on the number of recreational visits to forests and parks (results not shown but available upon request from the authors). An important concern related to our sampling approach is a potential "on-site" selection bias. By "on-site", we understand sites related to the amenities we are evaluating (parks and forests). One could imagine that respondents interviewed in the parks or the forests would pay more for having access to park or forests as they are users of these sites. However, statistical test did not reveal differences between the two groups (Section 4).

The variables used in the analysis are described in Table 4. We used the dummy variable OWNER to capture the variance of preference between owners and tenants. The household income has an important influence on the choice of residential location. In the model, the variable INCOME is the income per family quotient. The household income per family quotient accounts for the number of children, disabled and elderly people supported by the household, in the form of a rate (quotient). It is a method established by the French tax office. For example, the family quotient is one unit for a single person, two for a married couple, plus an extra half for each of the first two children and an additional unit for each child after the second. The adjusted income per family member is the ratio of household income to the family quotient index. This measure is more representative of the household's standard of living.

During the survey, the respondents stated their number of visits to peri-urban forests (referred to as NBVF) over the past 12 months. In our sample, $80 \%$ of the respondents had visited a peri-urban forest in Nancy during this period. On average, people had visited a forest 15 times over the past 12 months. Several respondents visited different forests during the period. In this case, we counted the forest that they visited the most frequently. In a recent study on forest recreation involving an online survey in Lorraine (Abildtrup et al., 2013), 96\% of respondents had visited a forest during the last 12 months, and the average number of forest visits per visitor was 27 times per year. Their participation rate and average number of visits are both higher than ours. We believe that this difference is mainly due to a self-selection bias in Abildtrup et al. (2013) and differences in the survey area. It can perhaps be expected that individuals who often visit a forest will be more willing to participate in a survey on forest recreation, and that this effect will be more pronounced in a Web-based survey compared to our direct interviews. Furthermore, our study only covered the urban agglomeration of Nancy, whereas the previous study covered all of Lorraine, including rural areas.

The variables "distance to peri-urban forest" (referred to as DISF) and "distance to park" (referred to as DISP) present the actual distance to the nearest forest and park from the respondent's house. The variable "scenic view" (referred to as SVIEW) of green spaces is a dummy variable. If the respondent has a view of green spaces from his/her house, then the value of this variable is equal to 1 . The view of green spaces could be forests or any type of urban green space that is included in our study. The size of the living space (referred to as SURF) is a typical characteristic of a house. It is normally correlated with many other housing characteristics such as the number of rooms, the number of garages, the size of the terrace, and other household spaces. We use this attribute to observe individuals' priorities when they have to choose between private housing attributes and environmental attributes. Another housing characteristic in the model is the private garden, referred to as PG. Since private green spaces may be a substitute for public green spaces, we tested whether or not having a private garden has an impact on the preferences for public green spaces.

We chose to measure the variation of the attribute PRICE in percentage like other residential choice studies (Liao et al., 2015; Phaneuf et al., 2013). The interviewers' impression from a pretest of the questionnaire was that the respondents better understood the housing price change in percentage rather than in a sum of money. As a result, the WTP estimated in this article is measured as a percentage of the respondent's current housing expenses.

Table 4

Description of variables and summary statistics.

\begin{tabular}{|c|c|c|c|c|c|c|}
\hline Variable & Description & Mean & Std. Dev. & Min & Max & Share \\
\hline \multicolumn{7}{|c|}{ Individual information ( $N=180$ observations) } \\
\hline OWNER & 1 if respondent is house owner; 0 if tenant & & & & & $48 \%$ \\
\hline INCOME & $=$ Household income/family quotient $/ € 1000$ & 2.03 & 1.11 & 0 & 5 & \\
\hline \multirow[t]{5}{*}{ NBVF } & Number of visits to forest over 12 months & & & & & \\
\hline & $=0$ if does not visit at all & & & & & $20.5 \%$ \\
\hline & $=1$ if $0<$ number visits $<12$ & & & & & $52.8 \%$ \\
\hline & $=2$ if $12 \leq$ number visit $<52$ & & & & & $21.1 \%$ \\
\hline & $=3$ if $52 \geq$ number visits & & & & & $5.6 \%$ \\
\hline PG & House with private garden $=1$; Otherwise $=0$ & & & & & $33 \%$ \\
\hline \multicolumn{7}{|c|}{ Information according to respondents' residences in reality ( $N=180$ observations) } \\
\hline DISF & Distance to forest $(\mathrm{km})$ & 5.59 & 5.06 & 0.01 & 28 & \\
\hline DISP & Distance to parks (km) & 2.20 & 3.86 & 0.001 & 20 & \\
\hline SURF & Living space of the house $(\mathrm{m} 2)$ & 86.57 & 70.74 & 26 & 650 & \\
\hline SVIEW & Scenic view of green spaces (dummy) & & & & & $65 \%$ \\
\hline
\end{tabular}

\footnotetext{
a The attribute levels of Alternative 1 and Alternative 2 in the CE are pivoted around the attribute value of respondent's current house.
} 


\section{Econometric specification}

\subsection{Econometric models of choice}

The Multinomial logit (MNL) model is the most frequently used model to explain discrete choices and it relies on the assumption of independence of irrelevant alternatives (IIA). This assumption states that the odds of the probability of any two alternatives to be chosen by the respondent are independent of the presence of any other alternative in the choice set (Hensher, Rose, \& Greene, 2005). Moreover, the MNL model assumes that the utility functions across respondents are identical, which means that preferences must be homogeneous. Recently, the ML and LC models have been popularly used to evaluate preference heterogeneity in choice studies. Both types of models relax the IIA property. The ML model investigates heterogeneity through the random coefficient approach (Alfnes, 2004; Aravena, Martinsson, \& Scarpa, 2014; Hoyos, 2010; Rouwendal \& Meijer, 2001; Train, 1998). The LC model classifies respondents into several classes and formulates their preference variation with a discrete distribution (Boxall \& Adamowicz, 2002; Kosenius, 2010; Scarpa \& Thiene, 2005). The preferences are homogeneous within each class. Since both the ML model and the LC model can be applied to account for preference heterogeneity (although the objective of this paper is not to compare estimation methods and models), by reporting and discussing the results of the two models, we are able to show that the main results of this study are not sensitive to the selection of model specification, and help to identify the most appropriate model.

\subsection{Mixed logit model}

The ML model accounts for heterogeneity by allowing model parameters to vary randomly over individuals. It is generally assumed that the preferences vary across respondents but not across choices of the same respondent (Revelt \& Train, 1998). A clustered specification is applied that allows for repeated choices for each individual.

In a given sample with $N$ respondents, each respondent $n$ faces $T$ choice situations. Every choice situation has a choice set of $J$ alternatives. The utility for respondent $n$ choosing alternative $j$ in the choice set in situation $t$ is:

$U_{n j t}=\beta_{n} X_{n j t}+\varepsilon_{n j t}, \quad n=1, \ldots, N, \quad j=1, \ldots, J, \quad t=1, \ldots, T$

where $X_{n j t}$ is the observed attribute vector and $\beta_{n}$ is a vector of individual-specific taste coefficients with a density function $f\left(\beta_{n} \mid \theta\right)$ where $\theta$ are the parameters of the distribution. The unobserved error term $\varepsilon_{n j t}$ is assumed to be Gumbel-distributed.

In a logit model, the probability of an individual $n$ to choose alternative $i$ conditional on knowing $\beta_{n}$ can be expressed by:

$P_{n}\left(i \mid \beta_{n}\right)=\frac{\exp \left(\beta_{n} X_{n i}\right)}{\sum_{J}^{j=1} \exp \left(\beta_{n} X_{n j}\right)}$

In the case of multiple choices for each respondent, the logit probability refers to the probability that the individual $n$ will make the sequence of $T$ choices specified as $t=\{1, \ldots, T\}$. Knowing that the probability of each choice is presented by Eq. (2), the logit probability of the observed sequence of choices conditional on knowing $\beta_{n}$ is given by:

$P_{n}\left(j_{n 1}, \ldots, j_{n T_{n}} \mid \beta_{n}\right)=\prod_{t=1}^{T} P_{n}\left(j_{n t} \mid \beta_{n}\right)$

where $j_{n t}$ represents the alternative chosen by individual $n$ in choice situation $t$. The unconditional logit probability that individual $n$ makes the observed sequence of choice $j$ is integrated over the distribution of $\beta$ :

$L_{n}(\theta)=\int P_{n}\left(j_{n 1}, \ldots, j_{n T_{n}} \mid \beta_{n}\right) f\left(\beta_{n} \mid \theta\right) d \beta$

In a ML model, the distribution parameters $\theta$ of vector $\beta$ can be specified with a continuous distribution such as normal, log-normal or triangular.

The log likelihood can be maximized using maximum simulated likelihood methods (Train, 2003), done in the present study using STATA 12 and the "mixlogit" package (Hole, 2007).

\subsection{Latent class logit model}

The LC model estimates the preference heterogeneity across respondents by using a number of classes with different values of taste parameters for each class. Assume that there are $C$ classes with different values of taste parameters $\beta_{c}=\left\{\beta_{1}, \ldots, \beta_{C}\right\}$. The probability of respondent $n$ that belongs to class $c$ is then denoted by $\pi_{n c}$, where $\pi_{n c} \in[0,1]$ and $\sum_{c=1}^{C} \pi_{n c}=1$.

With $z_{n}$ denoting the individual-specific characteristics, and with the class allocation model taking a logit form, the probability of respondent $n$ falling into class $c$ is given by:

$\pi_{n c}(\theta)=\frac{\exp \left(\theta_{c} z_{n}\right)}{\sum_{c}^{c=1} \exp \left(\theta_{c} z_{n}\right)}$

where $\theta=\left(\theta_{1}, \ldots, \theta_{C-1}\right)$ are class membership parameters. The $C$ th parameter is normalized to zero for identification (Greene, 2003, chap. 21).

The probability of individual $n$ of class $c$ choosing alternative $i$ is given by:

$P_{n i t}^{c}\left(i \mid \beta^{c}\right)=\frac{\exp \left(\beta X_{n i t}\right)}{\sum_{J}^{j=1} \exp \left(\beta X_{n j t}\right)}$

Assuming the class of individual $n$ is unknown, the unconditional logit probability for individual $n$ choosing alternative $j$ is then given by:

$L_{n}\left(j_{n 1}, \ldots, j_{n T_{n}} \mid \beta_{1}, \ldots, \beta_{C}\right)=\sum_{c=1}^{C} \pi_{n c}\left(\prod_{t=1}^{T} P_{n j t}\left(j_{n t} \mid \beta_{c}\right)\right)$

In the present study, the estimation of the LC model is done using the STATA12 "lclogit” package (Pacifico \& Yoo, 2012).

\subsection{Willingness-to-pay approach}

With the common two-step practice, which is also referred to as a model in preference space (Train \& Weeks, 2005), the marginal WTP for an attribute is calculated by the ratio of the attribute's coefficient to the price coefficient, which are obtained from econometric models such as ML and CL models. In the case of the ML model, the ratio of two randomly distributed parameters will cause a skewed distribution of WTP. Some approaches such as fixing the price's coefficient (i.e., imposing no heterogeneity in cost sensitivity) or specifying the price coefficient as log-normally distributed have been applied so that WTP values will not 'explode' (Meijer \& Rouwendal, 2006). For the LC model, the WTP measure is the weighted average of WTP for each class using the probability of class membership as weights. Because of its finite mixture structure, it is less affected by the distributional assumptions on parameters.

Train and Weeks (2005) suggested estimating the ML model in WTP space. Applying this approach, the WTP is directly estimated by reformulating the model in such a way that the WTP of attribute coefficients are directly obtained from the regression. Previous 
studies have shown that the WTP space models provide more reasonable estimated WTP values with distributions that have lower densities associated with extreme values (Train \& Weeks, 2005), whereas other studies found that applying estimations in WTP space made their models fit the data less well (Sonnier et al., 2007; Train \& Weeks, 2005). However, Scarpa, Thiene, and Train (2008) reported that the specification in WTP space had a better fit than the model in preference space in their empirical study. Based on Eq. (1), we then separate the price attribute from the vector of attributes, i.e., assume $\beta_{n} X_{n j t}=\alpha_{n} p_{n j t}+b_{n} X_{n j t}^{\prime}$, where $p_{n j t}$ denotes the price attribute and $X_{n j t}^{\prime}$ denotes a vector of other non-monetary attributes. The $\alpha_{n}$ is the random parameter for price and $\beta_{n}^{\prime}$ are individual random parameters of other non-monetary attributes. The utility for respondent $n$ choosing alternative $j$ in situation $t$ is:

$U_{n j t}=\alpha_{n} p_{n j t}+b_{n} X_{n j t}^{\prime}+\varepsilon_{n j t} \quad n=1, \ldots, N, \quad j=1, \ldots, J$,

$t=1, \ldots, T$

$\varepsilon_{n j t}$ is a random term that is Gumbel-distributed and whose variance is $\operatorname{Var}\left(\varepsilon_{n j t}\right)=k_{n}^{2}\left(\pi^{2} / 6\right)$, where $k_{n}$ is the scale parameter for the $n$th individual.

The WTP for attributes in preference space will be $-b_{n} / \alpha_{n}$. If we use the ML model to fit our data, then both the price parameter $\alpha_{n}$ and the attribute parameter $b_{n}$ are random. As a result, the distribution of WTP, which is a ratio of two random variables, will be skewed.

Train and Weeks (2005) presented the estimation of WTP by applying random parameter models in WTP space. They showed that dividing Eq. ( 8 ) by $k_{n}$ does not change the household's behavior and gives us a new error term $\varepsilon_{n j t}$, which is IID extreme valuedistributed. The variance of $\varepsilon_{n j t}$ is $\pi^{2} / 6$ :

$U_{n j t}=\lambda_{n} p_{n j t}+c_{n} X_{n j t}+\varepsilon_{n j t}$

where $\lambda_{n}=\alpha_{n} / k_{n}, \quad c_{n}=b_{n} / k_{n}, \varepsilon_{n j t}=\varepsilon_{n j t} / k_{n}$. Using the fact that the WTP for a given attribute is obtained through the ratio $\mathrm{WTP}_{n}=c_{n} / \lambda_{n}=b_{n} / \alpha_{n}$, Eq. (9) can be rewritten as:

$U_{n j t}=\lambda_{n}\left[p_{n j t}+\gamma_{n} X_{n j t}\right]+\varepsilon_{n j t}$

This specification is referred to as a utility in willingness-to-pay space. Apparently, Eqs. (9) and (10) describe the behaviors of individuals in the same way. In the case of a model in willingness-to-pay space, this problem of unrealistic skewed distributions can be avoided by directly specifying the distribution of the WTP parameter $\gamma_{n}$ since $\gamma_{n}=b_{n} / \alpha_{n}$. The model in willingness-to-pay space can be estimated using hierarchical Bayesian estimation or maximum simulated likelihood estimation (Train, 2003). In this study, the maximum simulated likelihood estimation is applied as in Thiene and Scarpa (2009). It is estimated with STATA 12 using the "gmnl" package (Gu, Hole, and Knox, 2013).

\subsection{Model specification}

Decision makers are often inclined to retain their current choice when faced with new options (Samuelson \& Zeckhauser, 1988). In our case, respondents may prefer to stay in their own dwelling. Therefore, an Alternative Specific Constant (ASC) is specified in the model for the status quo alternative in order to capture the systematic component of a potential status quo effect according to Scarpa, Ferrini, and Willis (2005). The vector $X_{n j t}$ of our model contains two groups of variables. The first group of variables includes random parameter variables. Our four random parameter variables in the ML model are the "distance to forest" (DISF), "distance to parks" (DISP), "scenic view" (SVIEW), and "the price" (PRICE). In order to account for the preference heterogeneity, we intended to define all attributes in the CE as random parameter variables. However, when we estimated the preference parameters with the mixed logit model, the standard deviation of the parameter "SURF" was not significant. We therefore redefined SURF as a fixed parameter variable. The random parameters were assumed to be normal distributed over households (Hensher \& Greene, 2003).

The second group of variables is estimated as non-random variables. The variable $\left(\mathrm{SURF}^{2}\right)$ is used to capture the scale effect of the living space of the house. It is assumed that living space has a concave relationship with WTP, i.e., the marginal WTP (MWTP) will decrease with the increase of living space. The effect of household characteristics on preferences is analyzed by including interaction terms between household characteristics and attribute variables. The household variables do not vary between the choice alternatives and can therefore not be separately estimated in the utility function. The interaction terms allow us to investigate the so-called deterministic heterogeneity around the means of the estimated parameters. The interaction term between "number of visits to forest" and "distance to forest" (NBVF*DISF) is used to test if respondents who visit forests more often will have a higher WTP to avoid living farther away from a forest than that of respondents who visit forests less often. Moreover, a considerable role in residential location choice could be played by family income. The interaction terms between the variable INCOME and other attributes are used to test this hypothesis. Since a private garden may be a substitute for urban parks, we included an interaction term PG*DISP to test this hypothesis. To observe potentially different behaviors of homeowners and tenants, we also included the interaction terms between OWNER and each CE attribute in our model.

\section{Estimation results}

Since $28.3 \%$ of the respondents in our sample were interviewed in parks and forests, we needed to test the on-site and off-site selection bias. The result of the Hausman test suggests that there is no significant difference between onsite sample data and offsite sample data (Prob $>\mathrm{Chi}^{2}=0.3091$ ). The results of MNL, ML and LC models are presented in Table 5. Since the IIA assumption is rejected at the $1 \%$ level according to the results of the Hausman test, the MNL estimates are not reliable. The results of the MNL model are presented only for completeness and for the comparison of estimates. Nylund, Asparouhov, and Muthén (2007) found that the superiority of the Bayesian Information Criterion (BIC) is evident compared to other information criteria such as the Akaike Information Criterion (AIC), consistent AIC (CAIC), and adjusted BIC for determining the number of classes in a LC model. In our case, the BIC suggested a 2-class LC. Since the ML and LC models are non-nested models, we applied the Vuong test to decide which one fit our data better (Greene, 2003; Hensher et al., 2015, p. 238; Vuong, 1989). The result of the Vuong test between the LC model and the ML model in Table $5(-16.952<-1.96)$ suggests that the ML model provides a better fit to the data than the 2-class LC model. The details of these results are available from the authors.

In the LC model, the variables "DISP", "SVIEW" and "PRICE" are significant in both classes. The negative coefficient of "DISP" shows that respondents avoid living farther away from parks. The positive coefficient on "SVIEW" implies that people are willing to have green scenery outside their window. In both classes, the respondents prefer less expensive housing since the coefficients of "PRICE" are negative.

A total of $40.6 \%$ of the respondents were assigned to class $A$. The parameter of the variable "ASC" is significant and positive in class A. It implies that members of class A prefer the status quo situation, i.e., they prefer their actual housing. The significant positive sign of the variable "OWNER*ASC" indicates that although the variable "ASC" is not significant in class B, the house owners in class B are more likely to choose their current house. There is an important 
Table 5

Parameter estimates for the MNL, ML and LC model.

\begin{tabular}{|c|c|c|c|c|}
\hline & \multirow[t]{2}{*}{ MNL } & \multirow[t]{2}{*}{ Mixed logit } & \multicolumn{2}{|c|}{ Latent class logit } \\
\hline & & & Class A & Class B \\
\hline \multicolumn{5}{|l|}{ Fixed parameters } \\
\hline ASC & $\begin{array}{l}0.739^{* * *} \\
(0.182)\end{array}$ & $\begin{array}{l}0.846^{* * *} \\
(0.240)\end{array}$ & $\begin{array}{l}3.175^{* * *} \\
(0.730)\end{array}$ & $\begin{array}{l}-0.670 \\
(0.391)\end{array}$ \\
\hline SURF & $\begin{array}{l}0.048^{* *} \\
(0.017)\end{array}$ & $\begin{array}{l}0.043^{*} \\
(0.021)\end{array}$ & $\begin{array}{l}0.018 \\
(0.027)\end{array}$ & $\begin{array}{l}0.111^{* *} \\
(0.038)\end{array}$ \\
\hline SURF2 & $\begin{array}{l}-8.48 \mathrm{e}-05^{* *} \\
(3.03 \mathrm{e}-05)\end{array}$ & $\begin{array}{l}-8.87 \mathrm{e}-05^{* *} \\
(3.31 \mathrm{e}-05)\end{array}$ & $\begin{array}{l}-5.46 \mathrm{e}-05 \\
(2.85 \mathrm{e}-05)\end{array}$ & $\begin{array}{l}-0.001^{* *} \\
(4.54 \mathrm{e}-04)\end{array}$ \\
\hline NBVF*DISF & $\begin{array}{l}-0.123^{*} \\
(0.057)\end{array}$ & $\begin{array}{l}-0.171^{*} \\
(0.085)\end{array}$ & $\begin{array}{l}-0.186^{*} \\
(0.090)\end{array}$ & $\begin{array}{l}-0.223 \\
(0.126)\end{array}$ \\
\hline INCOME*DISP & $\begin{array}{l}1.023^{* * *} \\
(0.194)\end{array}$ & $\begin{array}{l}1.565^{* * * *} \\
(0.378)\end{array}$ & $\begin{array}{l}0.656 \\
(0.635)\end{array}$ & $\begin{array}{l}1.134^{* * *} \\
(0.272)\end{array}$ \\
\hline PG*DISP & $\begin{array}{l}1.004^{*} \\
(0.452)\end{array}$ & $\begin{array}{l}1.617^{*} \\
(0.766)\end{array}$ & $\begin{array}{l}0.873 \\
(0.753)\end{array}$ & $\begin{array}{l}2.633^{*} \\
(1.295)\end{array}$ \\
\hline OWNER*ASC & $\begin{array}{l}0.841^{* * * *} \\
(0.249)\end{array}$ & $\begin{array}{l}1.125^{* * *} \\
(0.331)\end{array}$ & $\begin{array}{l}-2.831^{* * *} \\
(0.831)\end{array}$ & $\begin{array}{l}3.809^{* * *} \\
(0.769)\end{array}$ \\
\hline OWER*DISP & $\begin{array}{l}2.339^{* *} \\
(0.842)\end{array}$ & $\begin{array}{l}3.193^{*} \\
(1.419)\end{array}$ & $\begin{array}{l}1.539 \\
(1.920)\end{array}$ & $\begin{array}{l}-7.943 \\
(6.037)\end{array}$ \\
\hline OWNER*INCOME*DISP & $\begin{array}{l}-1.571^{* * *} \\
(0.342)\end{array}$ & $\begin{array}{l}-2.443^{* * *} \\
(0.647)\end{array}$ & $\begin{array}{l}-1.385 \\
(0.814)\end{array}$ & $\begin{array}{l}-1.192 \\
(7.973)\end{array}$ \\
\hline \multicolumn{5}{|l|}{ Random parameters } \\
\hline DISF & $\begin{array}{l}0.109 \\
(0.075)\end{array}$ & $\begin{array}{l}0.120 \\
(0.121)\end{array}$ & $\begin{array}{l}0.337 \\
(0.148)\end{array}$ & $\begin{array}{l}0.087 \\
(0.133)\end{array}$ \\
\hline DISP & $\begin{array}{l}-2.563^{* * *} \\
(0.485)\end{array}$ & $\begin{array}{l}-3.929^{* * * *} \\
(0.901)\end{array}$ & $\begin{array}{l}-1.334 \\
(1.476)\end{array}$ & $\begin{array}{l}-3.286^{* * *} \\
(0.692)\end{array}$ \\
\hline SVIEW & $\begin{array}{l}0.698^{* * * *} \\
(0.139)\end{array}$ & $\begin{array}{l}0.957^{* * * *} \\
(0.245)\end{array}$ & $\begin{array}{l}0.793^{* *} \\
(0.267)\end{array}$ & $\begin{array}{l}0.821^{* *} \\
(0.250)\end{array}$ \\
\hline PRICE & $\begin{array}{l}-7.550^{* * * *} \\
(1.021)\end{array}$ & $\begin{array}{l}-9.578^{* * *} \\
(1.665)\end{array}$ & $\begin{array}{l}-10.991^{* * *} \\
(2.178)\end{array}$ & $\begin{array}{l}-7.509^{* * *} \\
(1.667)\end{array}$ \\
\hline \multicolumn{5}{|l|}{ Std. Dev. of random parameters (ML model) } \\
\hline \multicolumn{2}{|l|}{ DISF } & $\begin{array}{l}0.343^{*} \\
(0.146)\end{array}$ & & \\
\hline DISP & & $\begin{array}{l}1.835^{* * * *} \\
(0.537)\end{array}$ & & \\
\hline SVIEW & & $\begin{array}{l}1.362^{* * *} \\
(0.388)\end{array}$ & & \\
\hline PRICE & & $\begin{array}{l}10.455^{* * *} \\
(2.805)\end{array}$ & & \\
\hline Class share & & & 0.406 & 0.594 \\
\hline Vuong test: comparison ofML and LC & & $-16.952^{* * *}<-1.96$ & & \\
\hline LL & -449.284 & -434.845 & -408.667 & \\
\hline Mcfadden $R^{2}$ & 0.242 & 0.263 & 0.302 & \\
\hline No. of choice observations & 540 & 540 & 540 & \\
\hline
\end{tabular}

Standard errors are in parentheses.

${ }^{*} p<0.1$.

** $p<0.05$.

*** $p<0.01$.

difference between the coefficient of "DISP" in class A (-1.334) and the one in class $B(-3.286)$. This result indicates that members of class A are less sensitive to distance to parks (DISP) than members of class B. Although distance to forest (DISF) did not affect the choices of members of both classes in general, the significance of NBVF*DISF in class A implies that respondents with a larger number of annual visits to a forest lose more utility if they live farther away from forests. The marginal loss of living farther away for a respondent visiting less than once per month is the sum of the coefficients on DISF and NBVF*DISF.

In brief, the results of the $\mathrm{LC}$ model supported the existence of preference heterogeneity in the sample.

In the ML model, all parameters are significant and have the expected sign except the distance to forest (DISF), which is not significant. In short, the results show that all respondents prefer larger, less expensive houses with a view of green spaces, and they do not prefer to live farther away from parks. The variable NBVF*DISF is significant at the $10 \%$ level. It implies that people who often visit forests do not prefer to live farther away from a forest. The standard deviations of random parameters are all significant, which also proves the existence of preference heterogeneity in the sample. Since the ML model proved itself to be preferable to the LC model, our WTP estimates are computed based on the results of the ML model.

\section{Welfare estimates}

Since the Vuong test suggests that the ML model is provides a better fit to the data than the 2-class latent class model (Table 5), we only estimated the WTP with the mixed logit model. The results obtained from the ML model in preference space and WTP space are reported in Table 6. The column "WTP space" presents the WTP parameters of the ML model in WTP space. The column "Preference space" presents the WTP estimates computed with the results of the ML model in Table 5 based on the Krinsky and Robb parametric bootstrapping technique. Comparing the results of the two approaches shows that all attributes have the same sign and that their absolute values are not very different. However, comparing the two "Standard Error" columns, we find that the standard errors of the mean marginal WTP of attributes estimated by the ML model 
Table 6

WTP estimates with mixed logit model in WTP space and preference space.

\begin{tabular}{|c|c|c|c|c|}
\hline \multirow[b]{2}{*}{ Variable } & \multicolumn{2}{|l|}{ WTP space } & \multicolumn{2}{|c|}{ Preference space } \\
\hline & Estimates & Std. Err. & Estimates & Std. Err \\
\hline \multicolumn{5}{|l|}{ Non-random parameters } \\
\hline ASC & $0.0745^{* * *}$ & 0.024 & $0.088^{* * *}$ & 0.030 \\
\hline SURF & $0.005^{* *}$ & 0.002 & $0.005^{* *}$ & 0.002 \\
\hline SURF2 & $-9.51 \mathrm{e}-06^{* * *}$ & $3.86 e-06$ & $-9.26 \mathrm{e}-06^{* * *}$ & $-3.70 e-06$ \\
\hline NBVF*DISF & $-0.018^{* *}$ & 0.009 & $-0.018^{* *}$ & 0.010 \\
\hline INCOME*DISP & $0.158^{* * *}$ & 0.041 & $0.163^{* * *}$ & 0.049 \\
\hline PG*DISP & $0.143^{*}$ & 0.079 & $0.168^{* *}$ & 0.088 \\
\hline OWNER*ASC & $0.114^{* * *}$ & 0.036 & $0.117^{* * *}$ & 0.042 \\
\hline OWER*DISP & $0.329^{* *}$ & 0.150 & $0.333^{* *}$ & 0.169 \\
\hline OWNER*INCOME*DISP & $-0.245^{* * *}$ & 0.069 & $-0.255^{* * *}$ & 0.080 \\
\hline \multicolumn{5}{|l|}{ Random parameters } \\
\hline DISF & 0.009 & 0.012 & 0.013 & 0.014 \\
\hline DISP & $-0.409^{* * *}$ & 0.097 & $-0.410^{* * *}$ & 0.116 \\
\hline SVIEW & $0.099^{* * *}$ & 0.023 & $0.099^{* * *}$ & 0.026 \\
\hline \multicolumn{5}{|c|}{ Std. Dev. of random parameters } \\
\hline DISF & $0.039^{* * *}$ & 0.013 & $0.033^{* *}$ & -0.016 \\
\hline DISP & $0.200^{* * *}$ & 0.053 & $0.176^{* * *}$ & -0.065 \\
\hline SVIEW & $0.131^{* * *}$ & 0.039 & $0.130^{* * *}$ & -0.044 \\
\hline
\end{tabular}

No. of respondents $=180$.

No. of choice observations $=540$.

McFadden's pseudo $R^{2}=0.2586$

log likelihood at convergence $=-438.4082$.

Significance level: ${ }^{* * *} 1 \%$; ${ }^{* *} 5 \% ;{ }^{*} 10 \%$.

in preference space are bigger than the ones of the ML model estimated in WTP space. The results with the lower standard errors are better because they are more precisely measured (the uncertainties are smaller). This implies that the results obtained from the ML model in WTP space are more efficient. This result is consistent with Hensher (2006) and Sonnier et al. (2007). As a result, we prefer to interpret the results of the ML model in WTP space.

The WTP for ASC is statistically significant at the $1 \%$ level in the ML model. All other attributes being equal, respondents are willing to pay $7 \%$ more for the status quo alternative, i.e., the houses they are actually living in. The interaction term OWNER*ASC is significant at the $1 \%$ level. Its parameter is positive and thus implies that the owners are willing to pay $11 \%$ more for staying in their actual houses than the renters.

People's WTP for having a forest in the vicinity is estimated in our model. The interaction term NBVF*DISF has a significant negative impact on individuals' preferences at the $5 \%$ level. This implies that when the number of visits to forests increases, the WTP to avoid that the house is farther away from peri-urban forest increases. The random parameter associated with the variable DISF is not significantly different from zero. This implies that the distance to peri-urban forests does not affect people's choices of a residential location in general. However, the statistical significance of the standard deviation parameter of DISF suggests that people have heterogeneous preferences for the distance between peri-urban forests and their homes.

We calculated the changes in willingness-to-pay (MWTP) of marginal changes in distance to forest and parks using the estimates of DISF and NBVF*DISF. The MWTP to avoid living farther away from a forest or a park is presented in Table 7 where we have measured the MWTP (in $€$ ) of housing price per square meter for homeowners and rents per month per square meter for tenants. For example, according to the base-line information of the housing market, an average-size home is $123 \mathrm{~m}^{2}$ for house owners and 64 for renters. The average price for a house of $123 \mathrm{~m}^{2}$ is $€ 158,250$. The average rent for a house of $64 \mathrm{~m}^{2}$ is $€ 544$. The MWTP of living close to forests for a house owner is equal to " $\left[0.018^{*}\right.$ Number of visits to forest* housing price]/size". People who visit forests less than once a month are not willing to pay more for living close to a forest.
If people visit forests more than once a month, the MWTP of homeowners and tenants is $€ 33.56 / \mathrm{m}^{2}$ and $€ 0.23 / \mathrm{month} / \mathrm{m}^{2}$, respectively. If their visit frequency is at least once a week, the MWTP of homeowners and tenants is $€ 56.27 / \mathrm{m}^{2}$ and $€ 0.37 / \mathrm{month} / \mathrm{m}^{2}$, respectively

The parameter of SURF is significantly different from zero at the $1 \%$ level and has a positive sign. In general, the WTP for one additional square meter of living space for an average-size home is $€ 815.24$ for homeowners and $€ 2.80 /$ month for tenants. The non-significant standard deviation parameter shows that the preference concerning living space is homogeneous. Not surprisingly, the variable SURF $^{2}$ has a significant effect at the $5 \%$ level and a negative impact. This implies that the marginal WTP for one extra square meter of living space will decrease when the living space increases.

The distance to parks (DISP) strongly affects respondents' choices of a residential location since the utility significantly decreases at the $1 \%$ level with increasing distance to parks. The mean of the parameter suggests that residents, on average, are willing to pay to avoid living farther away from parks. The standard deviation parameter of DISP is significantly different from zero at the $1 \%$ level. This shows that respondents' preferences for living near parks vary among households. However, combining this evidence of preference heterogeneity with the mean parameter estimate indicates that $98 \%$ of the respondents have a positive WTP for reducing the distance to parks from their home. The value of $98 \%$ is calculated as " $1-\Phi[-$ (mean parameter estimate/random parameter standard deviation $)]=1-\Phi[-(0.4092 / 0.1998)]$ ", where $\Phi[x]$ is the cumulative standard normal distribution.

The WTP parameter of the variable INCOME*DISP is significantly different from zero at the $1 \%$ level. The positive sign of the parameter of INCOME*DISP implies that wealthier families will pay a smaller portion of their housing expenses to avoid living one $\mathrm{km}$ farther away from parks. The variable OWNER*INCOME*DISP is significantly negative at the $1 \%$ level. This indicates that homeowners are willing to pay more to avoid living father from a park if their income increases. The variable PG*DISP has a significant impact on preferences at the $10 \%$ level. The positive sign of its parameter shows that people may substitute private gardens for parks since 
Table 7

WTP for being closer to forests and parks for house owners and renters in $€$.

\begin{tabular}{|c|c|c|c|c|c|c|}
\hline \multirow[t]{2}{*}{ MWTP Estimates } & \multicolumn{3}{|c|}{ Owner, $€ / \mathrm{m}^{2}$} & \multicolumn{3}{|c|}{ Renter, $€ /$ month $/ \mathrm{m}^{2}$} \\
\hline & $\mathrm{NBVF}=1$ & $\mathrm{NBVF}=2$ & $\mathrm{NBVF}=3$ & $\mathrm{NBVF}=1$ & $\mathrm{NBVF}=2$ & $\mathrm{NBVF}=3$ \\
\hline $\begin{array}{l}\text { Changing residential distance to forest by one } \mathrm{km} \text {, for } \\
\text { those visiting forests }\end{array}$ & $\begin{array}{l}10.86 \\
(11.65)\end{array}$ & $\begin{array}{l}33.57 \\
(17.09)\end{array}$ & $\begin{array}{l}56.27 \\
(26.84)\end{array}$ & $\begin{array}{l}0.07 \\
(0.07)\end{array}$ & $\begin{array}{l}0.23 \\
(0.11)\end{array}$ & $\begin{array}{l}0.37 \\
(0.18)\end{array}$ \\
\hline $\begin{array}{l}\text { Changing residential distance to a park by } 100 \text { meters, } \\
\text { for those with a private garden }\end{array}$ & $\begin{array}{l}16.42 \\
(8.65)\end{array}$ & & & $\begin{array}{l}-0.02 \\
(0.7)\end{array}$ & & \\
\hline $\begin{array}{l}\text { Changing residential distance to a park by } 100 \text { meters, } \\
\text { for those who do not have a private garden }\end{array}$ & $\begin{array}{l}34.84 \\
(10.81)\end{array}$ & & & $\begin{array}{l}0.12 \\
(0.04)\end{array}$ & & \\
\hline
\end{tabular}

Note: the standard errors are presented in parentheses.

MWTP is measured as the relative value of the respondent's current rent or house price.

having a private garden reduces respondents' WTP to avoid living farther away from a park.

Using the estimates of the variables DISP, INCOME*DISP, OWNER ${ }^{*}$ INCOME* DISP, PG*DISP and OWNER*DISP, we estimated the MWTP for living 100 meters closer to a park for middle-income homeowners and middle-income tenants in our sample. For homeowners who do not have a private garden, their MWTP is $2.7 \%$ of their current house's price ( $€ 34.84 / \mathrm{m}^{2}$ ) on average. However, for homeowners who have a private garden, their MWTP is reduced to $1.2 \%$ of their current house's price $\left(€ 16.42 / \mathrm{m}^{2}\right)$ on average. Tenants do not behave the same way. For tenants who do not have a private garden, their WTP is $1.4 \%$ of their actual rent ( $\left.€ 0.12 / \mathrm{month} / \mathrm{m}^{2}\right)$ on average. If tenants have their own private garden, their MWTP for the "distance to park" attribute is not significant. Therefore, our results show that homeowners' preferences in relation to parks are different from those of tenants, and private garden owners' preferences in relation to parks are different from those of people who do not have private gardens.

The mean parameter of the variable SVIEW is significantly different from zero at the $1 \%$ level, with a positive sign showing the importance of a view in the individual's choice of residential location. It is also important to consider the significance of the standard deviation parameter of SVIEW. Combining this evidence of preference heterogeneity with the mean parameter estimate indicates that $77.7 \%$ of respondents have a positive WTP for having a window view of green spaces. The value "77.7\%" is calculated as " $1-\Phi[-$ (mean parameter estimate/random parameter standard deviation $)]=1-\Phi[-(0.0993 / 0.1305)]$ ", where $\Phi[x]$ is the cumulative standard normal distribution. On average, respondents are willing to pay $9.9 \%$ more to have a scenic view of green spaces outside their window. Taking an average-size house for each group (owners and tenants) as an example, homeowners are willing to pay $€ 127.80 / \mathrm{m}^{2}$ and tenants are willing to pay $€ 0.84 / \mathrm{month} / \mathrm{m}^{2}$.

\section{Discussion}

This study focuses on the preferences of residents of the city of Nancy in terms of the environmental attributes of their houses, especially the distance to urban green spaces (e.g., peri-urban forests, parks) and the scenic view of green spaces. We used the CE method to observe how residents evaluate urban green spaces in a neighborhood when they make their location choices. Instead of presenting alternative residences independent of the current residence, we applied a pivot design to make the CE more realistic. Taking the respondent's current house or apartment as a reference alternative, the attributes of other alternatives revolve around the attributes of the reference alternative. Previous studies that chose to valuate urban green spaces through residential choice most frequently applied the hedonic pricing method. Considering the advantages of CE compared to hedonic pricing methods (see Section 2.1), we chose to estimate the value of urban green spaces by applying the stated preferences approach to residential choice modeling. The results of both of the ML and LC models supported the existence of preference heterogeneity. The marginal WTPs for attributes are estimated with a ML model both in preference space and WTP space. In the case of random parameter estimation, using the WTP space approach can avoid the shortcomings of the preference space approach.

Our study, based on a convenience sample, found that periurban forests have a significant recreation value for the local population. By incorporating interaction terms between distance and household variables, we are able to further estimate factors that determine the preference heterogeneity with respect to environmental attributes in households' residential choices. By reducing the distance to a forest, forest visitors can cut down their travel costs, including travel time. Although respondents who have not visited a forest do not have a significant WTP for living close to a forest, we found that respondents who had visited a forest at least one time during the last 12 months were willing to pay a higher price for living close to one. The WTP increases with the respondent's number of visit to a forest. This is consistent with the recreation literature where the WTP for a given recreational site decreases with the distance (e.g., Li \& Mattsson, 1995).

Our results indicate that living near parks is preferred by people in general. This result is consistent with previous hedonic pricing studies. After a review of 30 studies, Crompton (2001) found that the appraised values of homes close to parks and open spaces were generally $10-20 \%$ higher than comparable properties without such amenities. Morancho (2003) found that every 100 meters farther away from a green area leads to a drop of approximately $€ 1800$ in the total housing price in Castellon, Spain. Dehring and Dunse (2006) reported that being one meter closer to a city park leads to a $0.02 \%$ increase of real estate prices in Aberdeen, Scotland. In addition, we found that this preference differs among people. We surprisingly found that people's WTP for living closer to a park decreases when their income increases. This may result from the fact that the demand for public green spaces increases by less than the proportional change in an individual's income. Another possible explanation for this result is that wealthier families are less sensitive to travel cost. They are willing to pay more for visiting parks. However, if high-income families live in more expensive residences, then they in fact may pay a higher amount for these amenities in absolute terms. Furthermore, considering that wealthier families have more demands on other aspects of their homes, they in fact probably reduce the share for public green spaces in their housing expenses. Landry and Chakraborty (2009) found that the tree canopy share is higher in urban areas with higher incomes in Tampa, Florida, implying that higher income households have more substitutes for parks, e.g., street trees, in their demand for urban greenery. We also discovered that having a private garden can reduce the WTP for living close to a park, implying that the possession of a private garden can decrease the WTP for living close to a park. There are quite a few studies that focus on the substitution effect of private gardens on the value of public green spaces. For example, using the hedonic price model, Panduro and Veie (2013) did not find complementarity or substitutability between common 
areas and private gardens. Our results indicate that these two types of urban green spaces are substitutes.

We compared the choice behavior of homeowners and tenants. Homeowners are willing to pay less for living close to parks compared to tenants. However, this WTP of homeowners increases with their income. Besides valuating the WTP for living close to urban green spaces, we attempted to test the substitute effect between peri-urban forests and urban parks by including an interaction term between distance to forest and distance to parks. The term is not significant, indicating that parks and forests are not substitutes.

We also succeeded in estimating indirect use values such as the scenic value of the green spaces. Using the hedonic pricing method, recent studies found that the scenic view of green spaces has a positive effect on housing prices in Europe. Tyrvainen and Miettinen (2000) found that dwellings with a forest view were on average 4.9\% more expensive than dwellings with otherwise similar characteristics in Salo, Finland. Cavailhès et al. (2010) found that the housing price will be increased by $1.5-2 \%$ for a view of trees and fields in Dijon, France. Using the CE method, our study found similar results, implying that people can benefit from the amenities of green spaces without having access to them. Such information should be taken into account to evaluate different scenarios of urban landscape planning. In France, there are many private forests that are not open to the public, but that does not prevent them from providing amenities to the local population. However, this value of private green spaces is seldom integrated into urban planning processes.

\section{Conclusion}

The role of individual preference heterogeneity for urban green spaces in people's residential location choices is rarely explicitly treated in the literature on the valuation of green spaces. To our knowledge, this is the first application of CE to residential choice modeling in the literature on the valuation of green spaces. Applying a pivot style $C E$, this paper provides new evidence on the preference heterogeneity for urban green space of urban dwellers. When making housing choices, people's preference heterogeneity for distance to peri-urban forests is related to recreational use. The WTP for having peri-urban forests in the vicinity increases with the frequency of forest visits. Respondents' preferences for having urban parks in the vicinity are heterogeneous due to income differences and private garden ownership. Moreover, having a house with a private garden may substitute for being close to urban parks. The significant WTP for scenic views shows that residents can benefit from urban green spaces with and without visiting them.

In our study, we requested respondents to make trade-offs in the situation where only the five attributes in the CE varied and all of the other attributes remained the same. This is obviously cognitively demanding. Since the welfare estimates in our study correspond relatively well to previous results in the literature, we believe that the respondents were able to make these hypothetical choices. However, future studies should more explicitly investigate the respondents' considerations when making their choices. It is obvious that a person's residential location choice could be strongly affected by other unobserved factors such as schools, hospitals, etc. Therefore, applying our results to simulate residential distribution of the population, for example, will require additional data.

Our study has implications for land-use planning in urban areas, including the construction of an urban green belt, a peri-urban afforestation project, etc. This information is not only relevant for increasing the welfare of existing inhabitants by optimal land-use planning but also contributes to attracting new residents. This latter aspect is often an important objective for urban or regional policy makers.

\section{Acknowledgement}

This work was co-financed by a grant from the Lorrain region, France and European Forest Institute. It was also supported by the French National Research Agency (ANR) through the ARBRE Laboratory of Excellence, a part of the Investments for the Future Program (ANR11-LABX-0002-01). The authors would like to thank the "Communauté urbaine du Grand Nancy" (CUGN) for providing urban data of the city of Nancy. The authors would also like to thank the discussants from the BETA-LEF seminar, the 5th World Congress of Environmental and Resource Economists, for their helpful comments.

\section{References}

Abildtrup, J., Garcia, S., Olsen, B. S., \& Stenger, A. (2013). Spatial preference heterogeneity in forest recreation. Ecological Economics, 92, 67-77.

Adamowicz, W., Louviere, J., \& Williams, M. (1994). Combining revealed and stated preference methods for valuing environmental amenities. Journal of Environmental Economics and Management, 26, 271-292.

Alfnes, F. (2004). Stated preferences for imported and hormone-treated beef: Application of a mixed logit model. European Review of Agricultural Economics, 31(1), $19-37$.

Aravena, C., Martinsson, P., \& Scarpa, R. (2014). Does money talk?-The effect of a monetary attribute on the marginal values in a choice experiment. Energy Economics, 44, 483-491.

Barbosa, O., Tratalos, J. A., Armsworth, P. R., Davies, R. G., Fuller, R. A., Johnson, P., et al. (2007). Who benefits from access to green space? A case study from Sheffield UK. Landscape and Urban Planning, 83(2), 187-195.

Bockstael, N. E., \& McConnell, K. E. (2007). Some econometric issues. pp. 175-176. Environmental and resource valuation with revealed preferences: A theoretical guide to empirical models (Vol. 7) Springer Science \& Business Media.

Boxall, P. C., \& Adamowicz, W. L. (2002). Understanding heterogeneous preferences in random utility models: A latent class approach. Environmental and Resource Economics, 23(4), 421-446.

Brander, L. M., \& Koetse, M. J. (2011). The value of urban open space: Meta-analyses of contingent valuation and hedonic pricing results. Journal of Environmental Management, 92(10), 2763-2773.

Bullock, C. H. (2008). Valuing urban green space: Hypothetical alternatives and the status quo. Journal of Environmental Planning and Management, 51(1), 15-35.

Cavailhès, J., Brossard, T., Foltête, J. C., Hilal, M., Joly, D., Tourneaux, F. P., et al. (2010). GIS-based hedonic pricing of landscape. Environmental and Resource Economics, 44(4), 571-590.

Chiesura, A. (2004). The role of urban parks for the sustainable city. Landscape and Urban Planning, 68(1), 129-138.

Crompton, J. L. (2001). Parks and economic development. APA planning advisory service reports no. 502. Washington, DC: American Planning Association.

Dehring, C., \& Dunse, N. (2006). Housing density and the effect of proximity to public open space in Aberdeen, Scotland. Real Estate Economics, 34(4), 553-566.

Del Saz Salazar, S., \& García Menéndez, L. (2007). Estimating the non-market benefits of an urban park: Does proximity matter? Land Use Policy, 24(1), 296-305.

Earnhart, D. (2002). Combining revealed and stated data to examine housing decisions using discrete choice analysis. Journal of Urban Economics, 51(1), 143-169.

Ezebilo, E. E., Boman, M., Mattsson, L., Lindhagen, A., \& Mbongo, W. (2015). Preferences and willingness to pay for close to home nature for outdoor recreation in Sweden. Journal of Environmental Planning and Management, 58(2), 283-296.

Freeman, A. M.(1993). The measurement of environmental and resource values: Theory and methods. Washington, DC: Resources for the Future.

Giergiczny, M., \& Kronenberg, J. (2014). From valuation to governance: Using choice experiment to value street trees. Ambio, 43(4), 492-501.

Gilboa, I., Schmeidler, D., \& Wakker, P. (2002). Utility in case-based decision theory. Journal of Economic Theory, 105(2), 483-502.

Greene, W. (2003). Econometric analysis (5th ed.). Englewood Cliffs: Prentice Hall

Gu, Y., Hole, A. R., \& Knox, S. (2013). Fitting the generalized multinomial logit model in Stata. Stata Journal, 13(2), 382-397.

Hand, M. S., Thacher, J. A., McCollum, D. W., \& Berrens, R. P. (2008). Intra-regional amenities, wages, and home prices: The role of forests in the southwest. Land Economics, 84(4), 635-651.

Hanley, N., Wright, R. E., \& Koop, G. (2002). Modelling recreation demand using choice experiments: Climbing in Scotland. Environmental and Resource Economics, 22(3), 449-466.

Henley, N., Wright, R. E., \& Adamowicz, V. (1998). Using choice experiments to value the environment. Environmental and Resource Economics, 11(3-4), 413-428.

Hensher, D. (2004). Accounting for stated choice design dimensionality in willingness to pay for travel time savings. Transportation Research Part B: Methodological, $38,425-446$.

Hensher, D. (2006). How do respondents process stated choice experiments? Attribute consideration under varying information load. Journal of Applied Econometrics, 21(6), 861-878.

Hensher, D., \& Greene, W. (2003). Mixed logit models: State of practice. Transportation, 30, 133-176. 
Hensher, D. A., Greene, W. H., \& Rose, J. M. (2006). Deriving willingness-to-pay estimates of travel-time savings from individual-based parameters. Environment and Planning A, 38(12), 2365-2376.

Hensher, D., \& Rose, J. (2007). Development of commuter and non-commuter mode choice models for the assessment of new public transport infrastructure projects: A case study. Transportation Research Part A: Policy and Practice, 41, 428-443.

Hensher, D. A., Rose, J., \& Greene, W. H. (2005). Applied choice analysis. A primer. Cambridge: Cambridge University Press.

Hensher, D. A., Rose, J. M., \& Greene, W. H. (2015). Applied choice analysis: A primer (2nd ed.). Cambridge University Press.

Hole, A. R. (2007). Fitting mixed logit models by using maximum simulated likelihood. The Stata Journal, 7, 388-401.

Hoshino, T., \& Kuriyama, K. (2010). Measuring benefits of neighborhood park amenities: Application and comparison of spatial hedonic approaches. Environment and Resource Economics, 45(3), 429-444.

Hoyos, D. (2010). The state of the art of environmental valuation with discrete choice experiments. Ecological Economics, 69(8), 1595-1603.

Irwin, E. G. (2002). The effects of open space on residential property values. Land Economics, 78(4), 465-480

Kahnemann, D., \& Tversky, A. (1979). Prospect theory: An analysis of decisions under risk. Econometrica, 47(2), 263-291.

Kellett, J. E. (1982). The private garden in England and Wales. Landscape and Urban Planning, 9(2), 105-123.

Kim, J. H., Pagliara, F., \& Preston, J. (2005). The intention to move and residential location choice behaviour. Urban Studies, 42(9), 1621-1636.

Kosenius, A. K. (2010). Heterogeneous preferences for water quality attributes: The case of eutrophication in the Gulf of Finland, the Baltic Sea. Ecological Economics, 69(3), 528-538.

Kuhfeld, W. F. (2010). Marketing research methods in SAS experimental design, choice, conjoint, and graphical techniques (SAS $9.2 \mathrm{ed}$.).

Kuminoff, N. V., Parmeter, C. F., \& Pope, J. C. (2010). Which hedonic models can we trust to recover the marginal willingness to pay for environmental amenities? Journal of Environmental Economics and Management, 60(3), 1-16.

Lancaster, K. J. (1966). A new approach to consumer theory. Journal of Political Economy, 74, 132-157.

Landry, S. M., \& Chakraborty, J. (2009). Street trees and equity: Evaluating the spatial distribution of an urban amenity. Environment and Planning A, 41(11), 2651.

Li, C. Z., \& Mattsson, L. (1995). Discrete choice under preference uncertainty: An improved structural model for contingent valuation. Journal of Environmental Economics and Management, 28(2), 256-269.

Liao, F. H., Farber, S., \& Ewing, R. (2015). Compact development and preference heterogeneity in residential location choice behaviour: A latent class analysis. Urban Studies, 52(2), 314-337.

Louviere, J. J., Hensher, D. A., \& Swait, J. D. (2000). Stated choice methods: Analysis and applications. Cambridge University Press.

Louviere, J. J. (1992). Experimental choice analysis: Introduction and overview. Journal of Business Research, 24(2), 89-95.

Mansfield, C., Pattanayak, S. K., Mcdow, W., Mcdonald, R., \& Halpin, P. (2005). Shades of Green: Measuring the value of urban forests in the housing market. Journal of Forest Economics, 11(3), 177-199.

McFadden, D. (1974). Conditional logit analysis of quantitative choice behavior. In P. Zarembka (Ed.), Frontiers in econometrics (pp. 105-142). New York: Academic Press.

Meijer, E., \& Rouwendal, J. (2006). Measuring welfare effects in models with random coefficients. Journal of Applied Econometrics, 21(2), 227-244.

Morancho, A. m. (2003). A hedonic valuation of urban green areas. Landscape and Urban Planning, 66(1), 35-41.

Nylund, K. L., Asparouhov, T., \& Muthén, B. O. (2007). Deciding on the number of classes in latent class analysis and growth mixture modeling: A Monte Carlo simulation study. Structural Equation Modeling, 14, 535-569.

Pacifico, D., \& Yoo, H. (2012). lclogit: A Stata module for estimating latent class conditional logit models via the expectation-maximization algorithm. UNSW Australian School of Business Research Paper No. 2012 ECON 49. Available at SSRN: http:// ssrn.com/abstract $=2174146$
Panduro, T. E., \& Veie, K. L. (2013). Classification and valuation of urban green spaces - A hedonic house price valuation. Landscape and Urban Planning, 120, 119-128.

Phaneuf, D. J., \& Smith, V. K. (2005). Recreation demand models. Handbook of Environmental Economics, 2, 671-761.

Phaneuf, D. J., Taylor, L. O., \& Braden, J. B. (2013). Combining revealed and stated preference data to estimate preferences for residential amenities: A GMM approach. Land Economics, 89(1), 30-52.

Poudyal, N. C., Hodges, D. G., \& Merrett, C. D. (2009). A hedonic analysis of the demand for and benefits of urban recreation parks. Land Use Policy, 26(4), 975-983.

Prashker, J., Shiftan, Y., \& Hershkovitch-Sarusi, P. (2008). Residential choice location, gender and the commute trip to work in Tel Aviv. Journal of Transport Geography, $16,332-341$.

Revelt, D., \& Train, K. (1998). Mixed logit with repeated choices: Households' choices of appliance efficiency level. Review of Economics and Statistics, 80, 647-657.

Rouwendal, J., \& Meijer, E. (2001). Preferences for housing, jobs, and commuting: A mixed logit analysis. Journal of Regional Science, 41(3), 475-505.

Samuelson, W., \& Zeckhauser, R. (1988). Status quo bias in decision making. Journal of Risk and Uncertainty, 1(1), 7-59.

Sander, H. A., \& Polasky, S. (2009). The value of views and open space: Estimates from a hedonic pricing model for Ramsey County, Minnesota, USA. Land Use Policy, 26(3), 837-845.

Scarpa, R., Ferrini, S., \& Willis, K. (2005). Performance of error component models for status-quo effects in choice experiments. In R. Scarpa, \& A. Alberini (Eds.) Applications of simulation methods in environmental and resource economics. The economics of non-market goods and resource (Vol. 6) (pp. 247-273). Dordrecht, The Netherlands: Springer.

Scarpa, R., \& Thiene, M. (2005). Destination choice models for rock climbing in the Northeastern Alps: A latent-class approach based on intensity of preferences. Land Economics, 81(3), 426-444.

Scarpa, R., Thiene, M., \& Train, K. (2008). Utility in willingness to pay space: A tool to address confounding random scale effects in destination choice to the Alps. American Journal of Agricultural Economics, 90(4), 994-1010.

Sonnier, G., Ainslie, A., \& Otter, T. (2007). Heterogeneity distributions of willingness to-pay in choice models. Quantitative Marketing Economics, 5(3), 313-331.

Starmer, C. (2000). Developments in non-expected utility theory: The hunt for a descriptive theory of choice under risk. Journal of Economic Literature, 38 , 332-382.

Sustainable Development Committee of Nancy, France. 2025, Grand Nancy durable un Nouvel Art de Ville. Report 2011. http://conseildedeveloppementdurable. grand-nancy.org/.

Termansen, M., Zandersen, M., \& Mcclean, C. (2008). Spatial substitution patterns in forest recreation. Regional Science and Urban Economics, 38(1) $81-97$.

Thiene, M., \& Scarpa, R. (2009). Deriving and testing efficient estimates of WTP distributions in destination choice models. Environmental and Resource Economics, 44(3), 379-395.

Thorsnes, P. (2002). The value of a suburban forest preserve: Estimates from sales of vacant residential building lots. Land Economics, 78(3), 426-441.

Train, K. E. (2003). Discrete choice methods with simulation. Cambridge: Cambridge University Press.

Train, K. E. (1998). Recreation demand models with taste differences over people Land Economics, 230-239.

Train, K. E., \& Weeks, M. (2005). Discrete choice models in preference space and willingness-to-pay space. In R. Scarpa, \& A. Alberini (Eds.), Application of simulation methods in environmental and resource economics (pp. 1-16). Dordrecht: Springer.

Train, K. E., \& Wilson, W. W. (2008). Estimation on stated-preference experiments constructed from revealed-preference choices. Transportation Research Part B Methodological, 42(3), 191-203.

Tyrvainen, L., \& Miettinen, A. (2000). Property prices and urban forest amenities. Journal of Environmental Economics and Management, 39(2), 205-223.

Vuong, Q. (1989). Likelihood ratio tests for model selection and non-nested hypotheses. Econometrica, 57, 307-333.

Walker, J. L., \& Li, J. (2007). Latent lifestyle preferences and household location decisions. Journal of Geographical Systems, 9(1), 77-101. 